\section{Notch one for activating NOTCH}

\section{By Lauren Martz, Staff Writer}

Multiple studies in recent years have called into question the use of NOTCH inhibitors to treat cancer because of an increased risk of endothelial cell tumors seen in animal models. ${ }^{1}$ Now, researchers at Vanderbilt University have additional mechanistic evidence for this and have shown that downregulation of NOTCH signaling in fact helps tumors evade the immune system. ${ }^{2}$ Instead of blocking the pathway, the Vanderbilt team thinks restoring the signaling pathway should help treat some malignancies.

In a paper published in Cancer Research, David Carbone and colleagues showed that some cancers are able to suppress $\mathrm{T}$ cellmediated immunity by dampening NOTCH signaling. The team then found that restoring the pathway with a NOTCH-activating ligand called delta-like 1 (DLL1) restored immune function and decreased tumor growth.

Carbone is professor of medicine and cell biology, chair and professor of cancer biology and director of the Specialized Program of Research Excellence in Lung Cancer at Vanderbilt.

The team, which also included researchers from Meharry Medical College, showed that levels of NOTCH ligands were lower in bone marrow from patients with cancer than in marrow from healthy controls. In mice with tumors, compared with control mice, Dll1 mRNA levels were lower in bone marrow and protein was reduced in splenocytes, suggesting that cancer decreases NOTCH signaling specifically in the tumor microenvironment to suppress immunity.

The researchers also implanted mice with bone marrow cells transduced with Dll1-carrying retroviruses, followed eight weeks later by implantation of a tumor. In these mice, compared with mice given control bone marrow, tumor growth was inhibited. This indicates high DLL1 levels have a protective effect, which stands in contrast to research suggesting that blocking the closely related DLL4 helps treat cancer.

OncoMed Pharmaceuticals Inc. and GlaxoSmithKline plc have the anti-DLL4 antibody OMP-21M18 in Phase I testing to treat various cancers. Regeneron Pharmaceuticals Inc. and Sanofi are developing REGN421, an anti-DLL1 mAb that is in Phase I testing to treat solid tumors.

In addition to testing the effects of retrovirus-mediated overexpression of Dll1, the group also developed a soluble form of Dll1 that activated NOTCH signaling. In mouse models of murine fibrosarcoma and Lewis lung carcinoma (LLC), soluble Dll1 inhibited tumor growth and raised $\mathrm{T}$ cell levels to those found in tumor-free mice.
Notably in the LLC mice, Dll1 therapy was only effective in immunocompetent animals. Those data suggest the antitumor effects of DLL1 activation depend on the immune system.

Patrick Zweidler-McKay, associate professor in the Division of Pediatrics and section chief of pediatric leukemia and lymphoma at The University of Texas M.D. Anderson Cancer Center, told SciBX that activating DLL1 might restore the T cell function necessary for antitumor immunity. He added that work from both his lab and others suggests that NOTCH activation is capable of inducing tumor apoptosis.

"We have found that activating NOTCH actually stops growth of certain cancers like B cell leukemia, myeloid leukemia and neuroblastoma. We have been able to show the beneficial effects of NOTCH activation against cancer in cultures, but this is a therapeutic breakthrough that they have seen an effect in animals," ZweidlerMcKay said.

\section{Humanizing DLL}

Carbone told SciBX his team's next steps will include optimizing the soluble DLL1 ligand. The compound used in the study was a cluster that consisted of the extracellular domain of DLL1, the Fc part of the mouse IgG2A antibody, a biotinylated donkey antibody and the biotinbinding protein avidin.

He said the group has discussed humanizing the clustered molecule with several antibody companies and synthetic chemists.

"The clear next step would be to test the human ligand in a transgenic mouse system," said Bassil Dahiyat, president and CEO of Xencor Inc. "There are multiple NOTCH receptors and very many NOTCH ligands. Unfortunately, complex receptor families and interactions often shift from the mouse to humans, so the chance that this finding will actually translate is reduced."

Xencor is developing cancer antigen-targeted antibodies to stimulate the innate immune response against cancer, including XmAb5574, an anti-CD19 antibody in Phase I testing to treat chronic lymphocytic leukemia (CLL), and XmAb2513, an anti-CD30 antibody in Phase I testing to treat Hodgkin's lymphoma.

\section{To activate or not}

In addition to humanizing DLL1, the bigger question is whether activating $\mathrm{NOTCH}$ is a good strategy to treat cancer. Due to the complex effects of interfering with the NOTCH signaling pathway, academics and companies are split on whether inhibiting or activating NOTCH signaling is beneficial for cancers and whether the pathway should be a cancer target at all. 
Despite conflicting data and safety concerns about NOTCH inhibition, several companies have reached the clinic with NOTCH and DLL family ligand inhibitors for cancer. In addition to the DLL4 blockers from OncoMed and Regeneron, Aileron Therapeutics Inc. has a stapled peptide notch 1 (NOTCH1) inhibitor in preclinical testing to treat acute lymphoblastic leukemia (ALL), and Aveo Pharmaceuticals Inc. has AV-232, an anti-NOTCH1 antibody, in preclinical testing to treat cancer.

Aveo and Aileron did not respond to interview requests.

Carbone said he recognizes the potential association between increased NOTCH signaling and cancer risk but does not expect DLL1 to have such issues. "Another paper recently published shows that DLL1 expression in the tumor also inhibits tumor growth by interfering with angiogenesis,"3 he said.

In addition, he noted that inactivating $\mathrm{NOTCH}$ mutations are being discovered in cancers, suggesting that the pathway could have a tumor suppressor role. ${ }^{4}$

As for the risk of NOTCH inducing cancer, Zweidler-McKay thinks it all comes down to timing. "To have NOTCH-induced cancer, you need prolonged activation inside the cells. In mice, simply stimulating $\mathrm{NOTCH}$ with overexpression of the NOTCH ligands only produces $\mathrm{T}$ cell proliferation and not actual cancer," he said. "In an immunestimulating function, the ligands might be administered for a few weeks, and I don't think it is likely that short-term treatment with NOTCH-activating agents will lead to cancer."

Aside from any cancer-related risks, Michael Bordonaro cautioned that "NOTCH signaling is involved in many physiological and developmental functions. While the paper showed the ability to counteract the repression of $\mathrm{T}$ cell activity caused by the tumor, it is not clear what effects global infusions of NOTCH ligands will have on total immune function and whether there will be serious side effects specific to the immune response."

Bordonaro is an assistant professor of molecular biology at The Commonwealth Medical College. He did say the risk of immunerelated side effects could be addressed by increasing the specificity of action and tumor-targeting potential of the new NOTCH activators.

Carbone told SciBX that patent applications covering the work in cancer and other forms of immune suppression have been filed and are available for licensing.

Martz, L. SciBX 4(34); doi:10.1038/scibx.2011.953

Published online Sept. 1, 2011

\section{REFERENCES}

1. Yan, M. et al. Nature 463, E6-E7 (2010)

2. Huang, Y. et al. Cancer Res.; published online Aug. 8, 2011; doi:10.1158/0008-5472.CAN-10-4366

Contact: David P. Carbone, Vanderbilt University, Nashville, Tenn. e-mail: d.carbone@vanderbilt.edu

3. Zhang, J.-P. et al. Cancer Lett. 309, 220-227 (2011)

4. Stransky, N. et al. Science 333, 1157-1160 (2011)

COMPANIES AND INSTITUTIONS MENTIONED

Aileron Therapeutics Inc., Cambridge, Mass.

Aveo Pharmaceuticals Inc. (NASDAQ:AVEO), Cambridge, Mass.

The Commonwealth Medical College, Scranton, $\mathrm{Pa}$.

GlaxoSmithKline plc (LSE:GSK; NYSE:GSK), London, U.K.

Meharry Medical College, Nashville, Tenn.

OncoMed Pharmaceuticals Inc., Redwood City, Calif.

Regeneron Pharmaceuticals Inc. (NASDAQ:REGN), Tarrytown, N.Y.

Sanofi (Euronext:SAN; NYSE:SNY), Paris, France

The University of Texas M.D. Anderson Cancer Center, Houston, Texas

Vanderbilt University, Nashville, Tenn.

Xencor Inc., Monrovia, Calif. 